\title{
Sustainability assessment of dwellings - a comparison of methodologies
}

\author{
Joana Andrade (i) and Luís Bragança \\ Building Physics and Construction Technology Laboratory, Civil Engineering Department, University of Minho, \\ Guimarães, Portugal
}

\begin{abstract}
Building sustainability assessment tools (BSATs) aim to promote and rank the sustainability of building stock. This paper makes a deep comparative analysis on how dwellings are evaluated by five BSAT and one performance-based design tool. The comparison is based on: (i) the purpose of assessment; (ii) sustainability dimensions considered; (iii) indicators addressed; (iv) life cycle phases considered by the indicators; (v) type of indicators; (vi) measurements; (vii) aggregation processes; and (vii) life cycle phases during which the assessment was carried out. The evaluation showed that the scope of BSAT varies significantly as well as the life cycle phases addressed in the assessment. Financial issues are often excluded from the assessment. None of the schemes is totally quantitative or qualitative in their measurement system; all have different types of indicators and different ways to assess them. This research provides researchers and stakeholders with important inside knowledge on the tools that allow the development and construction of more sustainable buildings.
\end{abstract}

\section{ARTICLE HISTORY}

Received 14 August 2014

Accepted 20 January 2016

\section{KEYWORDS}

Sustainability; single-family buildings; building sustainability assessment; BREEAM; code for sustainable homes; LEED; SBTool ${ }^{\text {PT }}$-H; CASBEE; DGNB; ECOProP

\section{Introduction}

A building's influence on sustainability concerns is undeniable. Ideally, property development should lead to social quality improvement while mitigating environmental impacts economically and efficiently (Mateus, Braganca, and Koukkari 2008). To tackle this issue and to promote and rank building stock sustainability, there are several building sustainability assessment tools (BSATs) being developed throughout the world. These aim at reporting data to aid decision-making, design and building use, while considering the aspirations of sustainable construction, rather than just rating sustainability levels (Kaatz et al. 2006; Tarja Häkkinen et al. 2012). The tools should embrace the three main aspects of sustainability: environment, society and economy in a life cycle approach. Moreover, buildings must accomplish their own performance conditions as usability, durability, safety and comfort (typically included in the social dimension) (Blok et al. 2011). Nevertheless, the many existing BSATs are quite different from one another. Not only the scale of analysis varies, but also their timescale and scope. Some tend to address only one life cycle phase, while others account for the whole building life cycle. The same happens with 
building typology. Each tool tends to be specific for a building typology - office, residential, etc. (Andrade and Bragança 2012). Some are oriented towards building materials level, others towards building products, construction elements, the whole building or its neighbourhood.

Throughout the years, different studies have been published addressing the content of sustainability assessment methodologies (Erlandsson and Borg 2003; Bunz, Henze, and Tiller 2006; Fowler and Rauch 2006; Ding 2008; Haapio and Viitaniemi 2008; Alyami and Rezgui 2012; Berardi 2012; Chandratilake and Dias 2013; Lee 2013; Wallhagen et al. 2013; Castro, Mateus, and Bragança 2014). However, these comparisons tend to be more superficial, and do not discuss tool details (such as issues and parameters) and the way they were conceived and designed. Alyami and Rezgui (2012) pointed out the regionalism differences amongst well-known methodologies, and compared converging criteria in order to establish a starting point for the development of a new methodology to be applied in Saudi Arabia. Bunz, Henze, and Tiller (2006) studied building life cycle phases addressed during the assessment, whereas Ding (2008) analysed existing environmental assessment tools based on their characteristics and limitations when assessing a building. It is worth mentioning that these studies do not often express which building typology the subject methodologies are applicable to, and the comparisons are made regarding the scheme and not the specific methodology. However, in cases where this happens, office buildings are typically considered.

BSATs gather both quantitative and qualitative aspects. The former are more practical and easily measured, while the latter rely on subjective issues that depend on the aspirations of tool designers. Nevertheless, even in quantitative aspects, BSATs differ from one another in the calculation methods and issues assessed. In fact, even the terminology used differs from tool to tool, hampering comparisons. This fact is seldom addressed in comparisons and tool descriptions. The sustainability concept is already quite subjective and non-consensual, and therefore big differences amongst tools that are intended to quantify sustainability can hamper their use or jeopardise users' trust.

\section{Aim and scope}

This paper proposes to analyse and compare BSATs applicable to detached dwellings. Residential buildings account for $75 \%$ of European building stock floor space, $64 \%$ of which are single-family houses. The remaining $25 \%$ correspond to the non-residential sector and is quite heterogeneous. Nevertheless, housing floor area tends to increase over time as well as the demand for single occupancy housing (BPIE 2011). Together with the population increase, this leads towards clear implications on future resource sustainability. The aim of this research is to analyse and understand BSAT methods and their main objectives when quantifying the sustainability of single-family buildings.

Property clients are becoming more aware of environmental issues, and thus BSATs are often used merely as a marketing tool rather than a way to assure that buildings were designed on a sustainable basis without any ulterior motive other than contributing to a more sustainable world. Despite this reality, the study does not discuss the driving force behind each tool, but rather tries to understand the tool's scientific and methodological content, its applicability as well as how the tools differ from each other.

The comparison is based on eight critical aspects: 
(1) Purpose of assessment

(2) Sustainability dimensions considered

(3) Indicators addressed

(4) Life cycle phases considered by the indicators

(5) Type of indicators

(6) Measurements

(7) Aggregation processes; and

(8) Life cycle phases during which the assessment was carried out

\section{Procedure for comparison}

To compare BSAT, different aspects need to be addressed. In this work, a combination of different approaches from several authors, such as Blok et al. (2011), Fowler and Rauch (2006) and Andrade and Bragança (2012), was used. This comparison was based on the following questions:

(1) What is assessed?

(2) How is it assessed, and

(3) When is the assessment performed?

Each of the questions is focused on one or more aspects, according to Table 1. Research was based on literature review and on a comprehensive study of the tools' manuals and auxiliary materials.

\section{Tools to be compared}

This work focused on holistic and integrative approaches commonly used and/or well known in Europe. In a preliminary and broad analysis, 10 general systems were analysed:

Table 1. Aspects used for comparison of BSAT.

\begin{tabular}{|c|c|c|}
\hline Question & Aspect & Description \\
\hline \multirow[t]{4}{*}{ What is assessed? } & Purpose & $\begin{array}{l}\text { The methodologies address the whole building or just a part? Which } \\
\text { typology of buildings do they assess? }\end{array}$ \\
\hline & $\begin{array}{r}\text { Sustainability } \\
\text { dimensions }\end{array}$ & Are the three sustainability dimensions assessed? To what extent? \\
\hline & Indicators & Which are the indicators included in the methodology? \\
\hline & $\begin{array}{l}\text { Life cycle phases } \\
\text { addressed }\end{array}$ & Which are the life cycle phases considered during the assessment? \\
\hline \multirow[t]{3}{*}{ How is it assessed? } & Type of indicators & $\begin{array}{l}\text { Are the indicators quantitative or qualitative? Are they performance } \\
\text { or prescriptive indicators? }\end{array}$ \\
\hline & Measurement & How are the indicators measured? \\
\hline & Aggregation & $\begin{array}{l}\text { How is the aggregation made: through the sum up of credits or } \\
\text { weighting factors with normalization? }\end{array}$ \\
\hline $\begin{array}{l}\text { When is the assessment } \\
\text { performed? }\end{array}$ & Life cycle phases & In which life cycle phases are the methodologies applicable to? \\
\hline
\end{tabular}


- BREEAM

- LEED

- ATHENA

- Eco-Quantum

- SBTool $^{\mathrm{PT}}$

- CASBEE

- DGNB

- EcoProp

- OpenHouse

- LEnSE

The analysis started by identifying the assessment object of each scheme. It regarded the evaluation boundaries, as building materials, elements, the whole building or even the whole neighbourhood. This can vary from scheme to scheme. And its identification is quite important in order to select the tool that best fits the scope and purpose of the intended assessment. Table 2 summarises the building typologies addressed by each system and to which life cycle phases they are applicable.

Next, the group of tools was narrowed to six. Only those with an available scheme focusing on single-family houses and written in English or Portuguese were selected. These were:

(1) BREEAM: Code for Sustainable Homes (2010)

(2) LEED: LEED for Homes v4

(3) SBTool: SBTool ${ }^{\mathrm{PT}}-\mathrm{H}$ v2009/2

(4) CASBEE: CASBEE for Home (Detached House), 2007

(5) DGNB: DGNB for small residential buildings, 2013

(6) EcoProP 4.2.1.

The BREEAM Code for Sustainable Homes (CSH) derives from the first BSAT to appear and represents a building code in the UK; LEED for Homes is a market-driven tool; SBTool ${ }^{\mathrm{PT}}-\mathrm{H}$ is an adaptation to the Portuguese reality of the internationally developed SBTool; CASBEE was developed in a partnership between the Japanese government and industry; DGNB is the most recent tool and based on European Union standards requirements; and EcoProP is not a rating system as such but a tool to aid the construction of sustainable buildings at early design stages. Almost all the systems have different schemes according to the building typology and their life cycle stage at the time of the assessment. The characteristics of these six BSATs are summarised in Table 3.

\section{Results}

\section{What is assessed?}

\section{Sustainability dimensions}

The scope within each sustainability dimension is broad and can vary from tool to tool. All tools included in this study address to some extent the environmental performance of a building, as presented later in the paper. CSH, LEED for Homes and CASBEE for Homes 
Table 2. General panorama of each sustainability assessment system related to the life cycle during which the assessment occurs and the type of buildings covered (BRE Global Ltd 2014; U.S. Green Building Council 2014; Danatzko 2010; ATHENA 2014; Dobbelsteen and van Uffelen 2008; Eco-Quantum 2013; iiSBE 2014; Barbosa, Mateus, and Bragança 2013; JaGBC and JSBC 2014; German Sustainable Building Council 2010, 2014; VTT 2004; OpenHouse 2013; LEnSE Partners 2006).

\begin{tabular}{|c|c|c|c|c|c|c|c|c|c|c|}
\hline & \multicolumn{10}{|c|}{ Assessment methods } \\
\hline & BREEAM & LEED & SBTool $^{\mathrm{PT}}$ & ATHENA & Eco-Quantum & CASBEE & DGNB & EcoProP & LEnSE & Open House \\
\hline \multicolumn{11}{|l|}{ Life cycle phases where applicable } \\
\hline Pre-design & & & & $x$ & & * & & $x$ & $x$ & \\
\hline Design & $x$ & $\mathrm{x}$ & & & & & $\mathrm{x}$ & & & $x$ \\
\hline Existing buildings & $x$ & $x$ & $x$ & $x$ & $x$ & $x$ & $x$ & & $x$ & $x$ \\
\hline New buildings & $x$ & $x$ & $x$ & $x$ & $x$ & $x$ & $x$ & & $x$ & $x$ \\
\hline Refurbishment & $x$ & $x$ & $x$ & $x$ & & $x$ & & & $x$ & \\
\hline \multicolumn{11}{|l|}{ Type of building covered by each system } \\
\hline Building product & & & & & $x$ & & & & & \\
\hline Residential building (multi-storey) & $x$ & $x$ & $x$ & $x$ & & $x$ & $x$ & $x$ & $x$ & \\
\hline Homes (single family) & $x$ & $x$ & $x$ & $x$ & $x$ & $x$ & $x$ & $x$ & $x$ & \\
\hline Hotels & $x$ & $x$ & $x$ & & & $x$ & $x$ & & & \\
\hline Offices & $x$ & $x$ & $x$ & $x$ & & $x$ & $x$ & $x$ & $x$ & $x$ \\
\hline Schools & $\mathrm{x}$ & $\mathrm{x}$ & & & & $\mathrm{x}$ & $\mathrm{x}$ & $\mathrm{x}$ & & \\
\hline Healthcare & $\mathrm{x}$ & $\mathrm{x}$ & & & & $\mathrm{x}$ & & $\mathrm{x}$ & & \\
\hline Retail & $\mathrm{x}$ & $\mathrm{x}$ & & & & $\mathrm{x}$ & $\mathrm{x}$ & $\mathrm{x}$ & & \\
\hline Industrial & $x$ & $x$ & & $x$ & & $x$ & $x$ & & $x$ & \\
\hline Prisons & $\mathrm{x}$ & & & & & & & & & \\
\hline Restaurants & $\mathrm{x}$ & & & & & $\mathrm{x}$ & & & & \\
\hline Halls & $\mathrm{x}$ & $\mathrm{x}$ & & & & $\mathrm{x}$ & & & & \\
\hline Courts & $\mathrm{x}$ & & & & & & & & & \\
\hline Data Centre & $\mathrm{x}$ & & & & & & & & & \\
\hline
\end{tabular}


Table 3. Characteristics of BSAT.

\begin{tabular}{|c|c|c|c|c|c|c|}
\hline \multirow[b]{2}{*}{$\begin{array}{c}\text { Assessment } \\
\text { methods }\end{array}$} & \multicolumn{6}{|c|}{ Details } \\
\hline & Year & Country & Life cycle stages & Rating & Comments & Ref. \\
\hline $\mathrm{CSH}$ & $\begin{array}{l}\text { First version: } \\
2000^{\mathrm{a}} \\
\text { Version to be } \\
\text { addressed: } 2007\end{array}$ & UK & $\begin{array}{l}\text { Design } \\
\text { Post- } \\
\text { construction }\end{array}$ & $\begin{array}{l}\text { Six } \\
\text { levels }\end{array}$ & $\begin{array}{l}\text { BREEAM was the first } \\
\text { BSAT to be developed } \\
\text { and its first version } \\
\text { addressed office } \\
\text { buildings only } \\
\text { accounting for } \\
\text { environmental } \\
\text { impact. It is } \\
\text { mandatory to social } \\
\text { housing }\end{array}$ & $\begin{array}{l}\text { Department for } \\
\text { Communities and } \\
\text { Local Government } \\
\text { (2010) }\end{array}$ \\
\hline $\begin{array}{l}\text { LEED for } \\
\text { Homes }\end{array}$ & $\begin{array}{l}\text { First version: } 2005 \\
\text { Version to be } \\
\text { addressed: } 2013\end{array}$ & USA & $\begin{array}{l}\text { Design } \\
\text { Post- } \\
\text { construction }\end{array}$ & $\begin{array}{l}\text { Four } \\
\text { levels }\end{array}$ & $\begin{array}{l}\text { It is a credit system } \\
\text { instead of weights }\end{array}$ & $\begin{array}{l}\text { U.S Green Building } \\
\text { Council (2014) }\end{array}$ \\
\hline SBTool $^{\mathrm{PT}}-\mathrm{H}$ & $\begin{array}{l}\text { International } \\
\text { version: } 1996 \\
\text { Portuguese and } \\
\text { addressed } \\
\text { version: } 2009\end{array}$ & Portugal & $\begin{array}{l}\text { Construction } \\
\text { Post-construction }\end{array}$ & $\begin{array}{l}\text { Six } \\
\text { levels }\end{array}$ & $\begin{array}{l}\text { SBTool was developed } \\
\text { internationally and } \\
\text { was adapted to } \\
\text { different country } \\
\text { realities, such as } \\
\text { Portugal, Spain, Italy } \\
\text { or Czech Republic }\end{array}$ & $\begin{array}{l}\text { Mateus and } \\
\text { Bragança (2009) }\end{array}$ \\
\hline CASBEE & $\begin{array}{l}\text { First version: } \\
2001 \\
\text { Version to be } \\
\text { addressed: } 2007\end{array}$ & Japan & Design Construction & $\begin{array}{l}\text { Five } \\
\text { levels }\end{array}$ & & IBEC (2008) \\
\hline DGNB & $\begin{array}{l}\text { First version: } 2008 \\
\text { Version to be } \\
\text { addressed: } 2013\end{array}$ & Germany & $\begin{array}{l}\text { Early design/ } \\
\text { design } \\
\text { Post- } \\
\text { construction }\end{array}$ & $\begin{array}{l}\text { Three } \\
\text { levels }\end{array}$ & $\begin{array}{l}\text { Aspects related to the } \\
\text { site location are } \\
\text { addressed but do not } \\
\text { account for the final } \\
\text { sustainability score }\end{array}$ & $\begin{array}{l}\text { German } \\
\text { Sustainable } \\
\text { Building Council } \\
\text { (2014) }\end{array}$ \\
\hline EcoProP & & Finland & Early design/design & - & $\begin{array}{l}\text { It is not a certification } \\
\text { system, it is a } \\
\text { performance-based } \\
\text { method to aid the } \\
\text { design of more } \\
\text { sustainable buildings }\end{array}$ & VTT $(2004,2013)$ \\
\hline
\end{tabular}

${ }^{a}$ As 'EcoHomes'. The tool named CSH was launched in 2006.

do not consider economic aspects. Only the SBTool ${ }^{\mathrm{PT}}$, DGNB and EcoProP address all three sustainability dimensions.

\section{Sustainability indicators}

Sustainability indicators refer to impacts, positive and negative, arising from the building's existence (Bradley and Kibert 1998). These impacts can occur at different levels: (i) indoor, affecting directly the health and comfort of the inhabitants; (ii) locally, affecting the neighbourhood and building surroundings; and (iii) globally, mainly related to environmental impacts that affect the whole planet. Table 4 summarises the content of the subject BSAT.

In order to ease the comparison of the tools, a common terminology was established, focusing on the following categories:

(1) life cycle environmental impacts

(2) energy performance

(3) water efficiency 
Table 4. Main issues considered in the BSAT and their evaluation method.

\begin{tabular}{|c|c|c|c|c|c|c|}
\hline \multirow[b]{2}{*}{ Categories and issues } & \multicolumn{6}{|c|}{ Assessment methods } \\
\hline & $\mathrm{CSH}$ & LEED v4 & SBTool $^{\text {PT }}$ & DGNB & EcoProP & CASBEE \\
\hline \multicolumn{7}{|l|}{ Life cycle environmental impacts } \\
\hline Global warming potential & $\checkmark$ & - & $\checkmark$ & $\checkmark$ & $\checkmark$ & $\checkmark$ \\
\hline Eutrophication potential & $\checkmark$ & - & $\checkmark$ & $\checkmark$ & - & - \\
\hline Acidification potential & $\checkmark$ & - & $\checkmark$ & $\checkmark$ & $\checkmark$ & - \\
\hline Stratospheric ozone depletion potential & 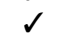 & - & $\checkmark$ & 1 & - & - \\
\hline Photochemical ozone creation & 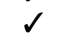 & - & 1 & 1 & $\checkmark$ & - \\
\hline Depletion of abiotic resources-elements & $\checkmark$ & - & - & - & $\checkmark$ & - \\
\hline Depletion of abiotic resources-fossil fuel & $\checkmark$ & - & - & - & $\checkmark$ & - \\
\hline Water extraction & $\checkmark$ & - & - & - & - & - \\
\hline Primary energy & $\checkmark$ & - & - & $\checkmark$ & $\checkmark$ & - \\
\hline \multicolumn{7}{|l|}{ Energy performance } \\
\hline Renewable energy & $\checkmark$ & $\checkmark$ & $\checkmark$ & $\checkmark$ & $\checkmark$ & $\checkmark$ \\
\hline Energy demand & $\checkmark$ & $\checkmark$ & $\checkmark$ & $\checkmark$ & $\checkmark$ & $\checkmark$ \\
\hline Energy monitoring & $\checkmark$ & $\checkmark$ & - & - & - & $\checkmark$ \\
\hline Low energy white goods & $\checkmark$ & $\checkmark$ & - & - & - & $\checkmark$ \\
\hline \multicolumn{7}{|l|}{ Water efficiency } \\
\hline Re-use/recycling & $\checkmark$ & $\checkmark$ & $\checkmark$ & $\checkmark$ & $\checkmark$ & $\checkmark$ \\
\hline Water consumption & $\checkmark$ & $\checkmark$ & $\checkmark$ & $\checkmark$ & $\checkmark$ & $\checkmark$ \\
\hline Water monitoring & - & $\checkmark$ & - & - & - & $\checkmark$ \\
\hline \multicolumn{7}{|l|}{ Waste } \\
\hline Construction waste management & 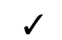 & $\checkmark$ & - & - & $\checkmark$ & $\checkmark$ \\
\hline Operational waste management & $\checkmark$ & - & $\checkmark$ & - & - & - \\
\hline \multicolumn{7}{|l|}{ Materials and resources } \\
\hline Materials reuse/recycling & $\checkmark$ & $\checkmark$ & $\checkmark$ & $\checkmark$ & - & $\checkmark$ \\
\hline Recycled content & - & $\checkmark$ & $\checkmark$ & - & - & $\checkmark$ \\
\hline Renewable sources & - & $\checkmark$ & - & - & - & $\checkmark$ \\
\hline Responsible sourcing & $\checkmark$ & $\checkmark$ & $\checkmark$ & $\checkmark$ & - & $\checkmark$ \\
\hline \multicolumn{7}{|l|}{ Site sustainability } \\
\hline Site selection & $\checkmark$ & $\checkmark$ & $\checkmark$ & - & $\checkmark$ & - \\
\hline Land use & $\checkmark$ & $\checkmark$ & $\checkmark$ & $\checkmark$ & $\checkmark$ & - \\
\hline Heat island effect & - & $\checkmark$ & $\checkmark$ & - & $\checkmark$ & $\checkmark$ \\
\hline Noise control & $\checkmark$ & - & - & - & $\checkmark$ & $\checkmark$ \\
\hline Development of community & - & $\checkmark$ & - & - & - & - \\
\hline Local ecology/biodiversity & $\checkmark$ & $\checkmark$ & $\checkmark$ & - & $\checkmark$ & $\checkmark$ \\
\hline \multicolumn{7}{|l|}{ Transports } \\
\hline Public transports & - & $\checkmark$ & $\checkmark$ & $\checkmark$ & $\checkmark$ & - \\
\hline Bicycle comfort & $\checkmark$ & $\checkmark$ & - & - & $\checkmark$ & - \\
\hline \multicolumn{7}{|l|}{ Health and comfort } \\
\hline Thermal comfort & - & $\checkmark$ & $\checkmark$ & $\checkmark$ & $\checkmark$ & $\checkmark$ \\
\hline Visual comfort & $\checkmark$ & - & $\checkmark$ & $\checkmark$ & $\checkmark$ & $\checkmark$ \\
\hline Acoustics & $\checkmark$ & - & $\checkmark$ & $\checkmark$ & $\checkmark$ & $\checkmark$ \\
\hline Indoor air quality & - & $\checkmark$ & $\checkmark$ & $\checkmark$ & $\checkmark$ & $\checkmark$ \\
\hline Ventilation & - & $\checkmark$ & $\checkmark$ & - & $\checkmark$ & $\checkmark$ \\
\hline Water quality & - & - & - & - & - & - \\
\hline \multicolumn{7}{|l|}{ Service quality } \\
\hline Flexibility/adaptability & - & - & - & $\checkmark$ & $\checkmark$ & $\checkmark$ \\
\hline Disable persons access & - & - & - & $\checkmark$ & $\checkmark$ & $\checkmark$ \\
\hline Safety and security & $\checkmark$ & - & - & $\checkmark$ & $\checkmark$ & $\checkmark$ \\
\hline Earthquake resistance & - & - & - & - & $\checkmark$ & $\checkmark$ \\
\hline Maintenance management & - & - & - & $\checkmark$ & $\checkmark$ & $\checkmark$ \\
\hline Spatial efficiency & - & - & - & - & $\checkmark$ & $\checkmark$ \\
\hline User controllability & - & - & - & - & $\checkmark$ & $\checkmark$ \\
\hline Functionality & - & - & - & - & $\checkmark$ & $\checkmark$ \\
\hline Fire prevention & - & - & - & $\checkmark$ & $\checkmark$ & $\checkmark$ \\
\hline Ease of disassembly, re-use or recycling & - & - & - & $\checkmark$ & $\checkmark$ & - \\
\hline
\end{tabular}


Table 4. Continued.

\begin{tabular}{lcccccc}
\hline & \multicolumn{5}{c}{ Assessment methods } \\
\cline { 2 - 6 } Categories and issues & CSH & LEED v4 & SBToo PT $^{\text {PT }}$ & DGNB & EcoProP & CASBEE \\
\hline $\begin{array}{l}\text { Durability } \\
\text { Cultural and aesthetics }\end{array}$ & $\checkmark$ & $\checkmark$ & - & - & $\checkmark$ & $\checkmark$ \\
Culture and heritage & - & - & - & - & $\checkmark$ & - \\
$\begin{array}{l}\text { Aesthetic quality } \\
\text { Project management }\end{array}$ & - & - & - & - & $\checkmark$ & - \\
$\begin{array}{l}\text { Quality of the project } \\
\text { Construction phase }\end{array}$ & - & $\checkmark$ & - & $\checkmark$ & $\checkmark$ & - \\
Integrated planning & $\checkmark$ & - & - & $\checkmark$ & $\checkmark$ & - \\
Construction site impacts & - & $\checkmark$ & - & $\checkmark$ & $\checkmark$ & - \\
Economic aspects & $\checkmark$ & $\checkmark$ & - & - & $\checkmark$ & - \\
LCC & & & & & & \\
Value stability & - & - & $\checkmark$ & $\checkmark$ & $\checkmark$ & - \\
\hline
\end{tabular}

(4) waste

(5) materials and resources

(6) Site Sustainability

(7) transport

(8) health and comfort

(9) service quality

(10) cultural and aesthetics

(11) project management

(12) economics.

Within each of these categories, several indicators were defined to reflect different aspects of the overall category. The assessment process and a discussion of the indicator typology will be presented later on.

The tools might seem superficially similar in some categories, but when studied in detail, it became clear that they are quite often different from each other.

As can be seen in Table 4, LEED and CSH (BREEAM) pay more attention to environmental and energy-related aspects, while CASBEE is more thorough on life and service quality. DGNB, as the newest system, goes beyond the three sustainability pillars environment, society and economy - to embrace technical, functional and processrelated aspects and coping with the new European standards for building sustainability. EcoProP is a design aid tool, and therefore it is more comprehensive, reaching several design specificities. SBTool ${ }^{\mathrm{PT}}-\mathrm{H}$ was developed to evaluate home sustainability, based on the international SBTool matrix, and thus encompasses environmental, economic and social impacts. The latter comprises essentially comfort-related issues, not focusing on technical and functional aspects.

Taking a closer look at Table 4, it becomes clear that issues related to energy efficiency and renewability, and water efficiency and reuse are considered by all six tools. On the other hand, only SBTool ${ }^{\mathrm{PT}}-\mathrm{H}, \mathrm{DGNB}$ and EcoProP consider economic issues, while cultural and aesthetics are only taken into consideration in EcoProP.

Within each category, even if the issues addressed are the same, the procedure to quantify them varies, such as the assessment of life cycle environmental impacts. CHS and DGNB follow EN 15804:2012 categories and recommendations, whilst CSH also considers 
other environmental impact categories, giving them more than $50 \%$ of the total life cycle assessment (LCA) weighting. On the other hand, CASBEE only considers global warming potential. This issue is measured by taking into account the results from other CASBEE indicators to estimate the life cycle $\mathrm{CO}_{2}$ emissions, encompassing construction, use, renovation, demolition and disposal phases. In addition to having different impact categories addressed in different ways, the boundaries considered for the assessment are also distinctive.

Another relevant example is energy efficiency as it is significant for all tools. DGNB, $\mathrm{SBTool}^{\mathrm{PT}}-\mathrm{H}, \mathrm{EcoProP}$ and CASBEE account for renewable energy used within the building, and assess the energy demand during the use phase. In this way, not just the reduction of fossil fuel energy is rewarded, but also the effective energy efficiency, which is often confused with the former (Araújo, Almeida, and Bragança 2013). In the CSH system the main energy-related indicators ('Energy and $\mathrm{CO}_{2}$ emissions' and 'fabric energy efficiency') account essentially for the consumption of non-renewable energy and not for the real energy-consumption reduction. Other energy-related indicators, such as 'energy labelled white goods' or 'drying spaces', acknowledge energy-consumption reduction, no matter the source. CSH, CASBEE and LEED underline that users' behaviour can highly influence the energy consumption, as the three tools promote the existence of an energy-consumption control device.

A major difference between the tools is the inclusion of service quality issues. These issues play an important role in DGNB, ECoProP and CASBEE. DGNB is the newest tool and hence follows new European Standards, giving emphasis to these new requirements and guidelines on how sustainability should be assessed. CASBEE, in turn, takes into consideration functional quality and resilience issues, as Japan is a country with a high incidence of natural disasters. EcoProP, as a design aid tool, encompasses safety, stability, usability and durability concerns as they represent legal requirements.

\section{Life cycle phases}

The building life cycle can broadly be split in planning/design, production of building materials, construction, use/operation, maintenance, demolition/deconstruction and disposal. Single-family buildings are no exception from other building typologies. Each stage has a purpose, involving different players and different sustainability issues. The life cycle approach confirms that improving one type of impact at one stage can have negative impacts in another. This means that the more the impacts of each life cycle are included in the assessment, the more accurate and correct the assessment will be, and hence enrich the building's sustainability. Regarding BSAT for single-family buildings,

Table 5. Life cycle phases considered.

\begin{tabular}{lcccccc}
\hline & \multicolumn{5}{c}{ Assessment methods } \\
\cline { 2 - 7 } Life cycle phases & CSH & LEED & SBTool $^{\text {PT }}$ & DGNB & EcoProP & CASBEE \\
\hline Project/design & & $\mathrm{x}$ & & $\mathrm{x}$ & $\mathrm{x}$ & \\
Production & $\mathrm{x}$ & $\mathrm{x}$ & $\mathrm{x}$ & $\mathrm{x}$ & $\mathrm{x}$ & $\mathrm{x}$ \\
Construction & $\mathrm{x}$ & $\mathrm{x}$ & & $\mathrm{x}$ & $\mathrm{x}$ & $\mathrm{x}$ \\
Use/operation & $\mathrm{x}$ & $\mathrm{x}$ & $\mathrm{x}$ & $\mathrm{x}$ & $\mathrm{x}$ & $\mathrm{x}$ \\
Maintenance & $\mathrm{x}$ & & $\mathrm{x}$ & $\mathrm{x}$ & $\mathrm{x}$ & $\mathrm{x}$ \\
Demolition/deconstruction & $\mathrm{x}$ & & $\mathrm{x}$ & $\mathrm{x}$ & $\mathrm{x}$ & $\mathrm{x}$ \\
Disposal & $\mathrm{x}$ & & & & $\mathrm{x}$ \\
\hline
\end{tabular}


they tend to include the phases that represent a major role in building sustainability. In this sense, Table 5 shows the life cycle phases considered and assessed by the six tools. DGNB, EcoProP and CASBEE have the greater coverage, although the other tools include most of the major life cycle stages. Considering all the tools, only EcoProP accounts for all life cycle stages and, together with DGNB and LEED, cover the design stage. This phase is essentially considered in one single category, mainly referred to as 'project quality'. It considers if there is integrated planning or if sustainability principles and specialists are taken into consideration. On the other hand, all tools cover the production phase.

The way the tools cover all stages varies. The same stage can be addressed by different criteria with different evaluation methods. For instance, LEED is the only tool embedding the production phase through the quantification of environmentally friendly products, as well as the consideration of the distance from the production site to the building site. All the other tools considering this stage do it through life cycle environmental assessment.

The construction phase is addressed either by LCA or by parameters accounting for the impacts in the neighbourhood and waste production during construction activities. The $\mathrm{SBTool}^{\mathrm{PT}}-\mathrm{H}$ is the only tool that does not account for this phase, not even through LCA. All other tools adopt similar approaches. None of the schemes address social aspects for the construction workers.

All the schemes take into consideration social and environmental aspects during the operational phase. Maintenance is addressed in a similar way as construction by LCA and by a number of functional features.

Regarding the last two phases, all schemes, except LEED, account for disposal, while EcoProP and CASBEE consider only demolition. Disposal and demolition are considered by LCA. However, the extent of this consideration depends on the environmental categories addressed in each scheme.

\section{How is it assessed?}

\section{Type of indicators and measurement}

Each tool seeks to assess sustainability through a set of specific criteria, which can be actions taken during design, inclusion of certain devices and actual performance of the building, amongst others. The various tools do this in different ways, which makes comparisons of aggregated assessments difficult. The life cycle stage in which a building is assessed constrains the nature, quality and quantity of available information. Thus, the diversity and non-standard procedures lead to different BSAT evaluating the same issue in different ways, further hampering the cross-comparisons and understanding of the results.

According to Blok et al. (2011), indicators may be quantitative or qualitative, addressing 'procedural/procedure', 'feature' or 'performance' issues. Procedural indicators are designed to assess actions taken to improve performance; Feature indicators seek to validate the existence of a certain device or technical solution included in the building, without measuring the improvement on the building's performance. Finally, Performance indicators directly measure the subject issue and its improvement, typically comparing it with the common solution. Performance indicators can be of two kinds. The first - hypothetical performance - is assessed through estimation/simulation, typically addressed during design. It should be confirmed after construction to validate the results. The second 
considers those that address real performance after construction. Nevertheless, aspects such as primary energy needs are addressed through software simulation, even in postconstruction phases. This will avoid undesired behaviour by the occupants affecting the buildings' performance possibilities. On the other hand, air-tightness or acoustic comfort is evaluated in situ and the effective performance is quantified in the post-construction phase.

Indicators in all methodologies aim to address/reward a specific impact/benefit, which can seldom be directly or exactly quantified. Thus, most methodologies rely on simplifications or indirect methods/measures. BSATs take into account measures that are intended to improve or influence the wider impact of the building and which can be taken into consideration while designing the building. This occurs, for instance, in LEED or the SBTool ${ }^{\mathrm{PT}}$-H with regard to local biodiversity and in $\mathrm{CSH}$ with energy-efficiency measures. With this in mind, Table 6 shows how the six single, family BSATs evaluate the sustainability criteria. To complement this data and perceive the extension of the use of each evaluation approach and their relevance to the tool assessment methodology, Figure 1 shows graphically the distribution of indicator typologies in each BSAT. Figure 1(a) presents the relation between indicator typologies and the total number of indicators within each BSAT, while Figure 1 (b) presents the relation based on the importance (weight) given to each indicator.

Table 6 and Figure 1 reinforce that no two tools are alike. All tools embed the three typologies (Performance, Procedure and Feature) except for EcoProP, which only contains Performance and Procedural indicators. The focus of the tools varies; there is no dominant pattern of one typology over another. Nevertheless, Figure 1(a) shows there is a predominance in the use of Performance issues in SBTool ${ }^{\mathrm{PT}}-\mathrm{H}$ and EcoProP, while the other tools use the three typologies in a more balanced way. On the other hand, Figure 1(b) shows that when considering the importance (weight or credits) given to the issues, Performance indicators take a more relevant role. EcoProp is not a certification system, but a framework to help designers establish their performance goals during the design process, even if the objective is to obtain a certain level of sustainability with any of the certification systems presented. For this reason, EcoProP does not appear in Figure 1(b). All Performance

Table 6. Type of indicators.

\begin{tabular}{|c|c|c|c|c|c|c|}
\hline \multirow[b]{2}{*}{ Categories } & \multicolumn{6}{|c|}{ Assessment methods } \\
\hline & $\mathrm{CSH}$ & LEED v4 & SBTool $^{\mathrm{PT}}$ & DGNB & EcoProP & $\overline{\text { CASBEE }}$ \\
\hline LCA & 0 & - & 0 & 0 & 0 & 0 \\
\hline Energy performance & $\square$ & $\square$ & 0 & 0 & 0 & $\square$; \\
\hline Water efficiency & 0 & $\square$ & 0 & $\Delta$ & 0 & $\square$ \\
\hline Waste & $\Delta \square$ & 0 & $\square$ & - & 0 & $\Delta$ \\
\hline Materials and resources & 0 & $\mathbf{0} \square$ & $\overrightarrow{0} \Delta \square$ & $0 \square$ & - & $\Delta \square$ \\
\hline Site sustainability & $\mathbf{O}$ & $\mathbf{0} \Delta$ & 0 & $\Delta \square$ & $\Delta$ & $\Delta$ \\
\hline Transports & $\square$ & - & 0 & $\square$ & 0 & - \\
\hline Health \& comfort & $\vec{O} \square$ & $\Delta \square$ & $\square$ & 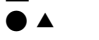 & 0 & $\square$ \\
\hline Service quality & $\square$ & $\Delta$ & - & $\mathbf{\Delta} \square$ & 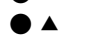 & $\Delta \square$ \\
\hline Cultural \& aesthetics & - & - & - & - & $\Delta$ & - \\
\hline Project management & $\Delta$ & $\Delta$ & & $\Delta$ & $\Delta$ & - \\
\hline Economic aspects & - & - & 0 & 0 & 0 & - \\
\hline Others & $\mathbf{\Delta} \square$ & $\Delta$ & - & $\Delta$ & - & - \\
\hline
\end{tabular}

Notes:

Performance;

- Feature 


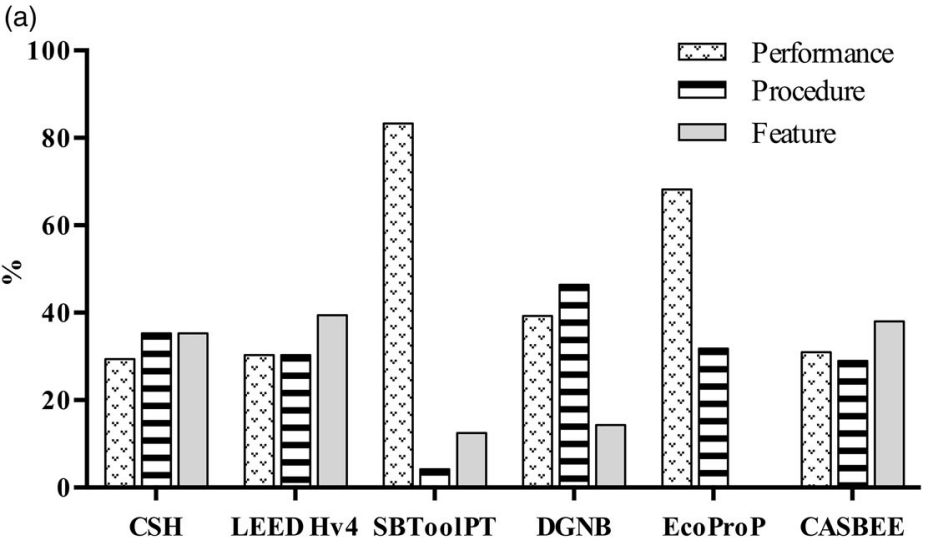

(b)

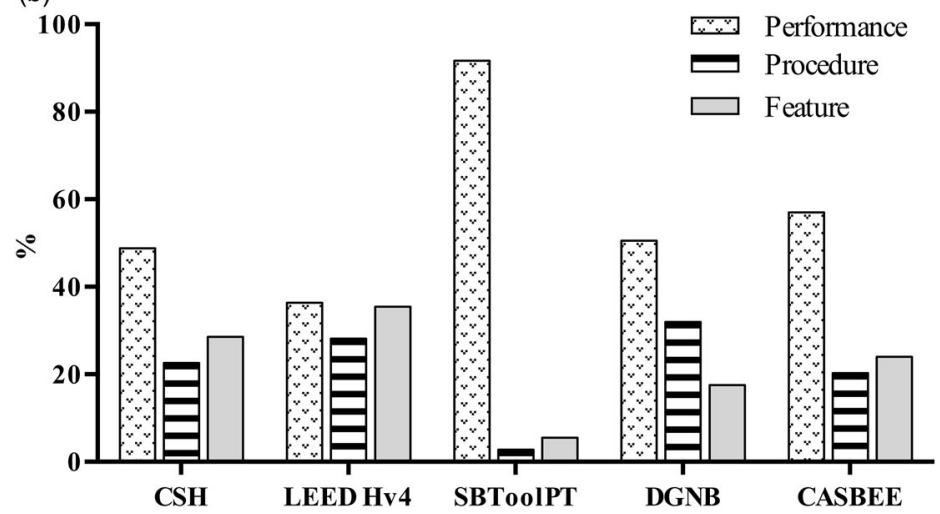

Figure 1. (a) Distribution of indicator typologies. Relation between number of indicators addressed in a certain way and the total number of indicators. (b) Distribution of indicator typologies based on the weights given to those indicators.

indicators are estimates, as there are no measures in situ in post-construction to assess building behaviour.

LCA-related indicators are the only ones addressed by the same indicator typology by all tools - Performance. The main aspects related to Energy Performance are also considered through Performance.

The SBTool ${ }^{\mathrm{PT}}-\mathrm{H}$ uses mainly Performance indicators, which are present in all categories except in 'Waste' (Table 6). In addition, when considering Figure 1(a) and 1(b), greater importance is given to those indicators.

CSH has 6 of the 13 categories assessed by Performance indicators, 6 by Procedure and 6 by Feature, as some categories are measured with more than one issue typology. LCA is only assessed by Performance. Transport is assessed by Feature and Project Management by Procedure. All other categories are addressed by more than one typology. Figure 1 allows verifying that although Performance issues are fewer in number than Procedural and Feature issues, they are the main contributors to the overall sustainability score.

LEED has only 4 out of 13 categories addressed by Performance criteria. Only the 'Waste' category is considered by Performance. 'Service Quality' and 'Project Management' are 
Procedural categories. Within categories, LEED has the same number of Performance and Procedural criteria that are exceeded by the number of Feature indicators. This can be explained by the fact that LEED is a checklist-based tool. Even though there are more Feature criteria than Performance criteria, the latter have a greater contribution to the final score, as in all other tools (Figure 1).

DGNB has more Procedural indicators than the other three typologies. Only 'Water' and 'Project Management' are addressed by this tool. Performance is the only assessment typology in 'LCA', 'Energy Performance' and 'Economic Aspects'. 'Transport', as in CSH, is considered through Feature indicators. All other categories have a combination of assessment procedures.

It is worth mentioning that CASBEE is quite different from other subject rating systems due to its assessment procedure, which is divided into two main groups: environmental quality of the house itself $(Q$, and environmental load imposed by the house on the external environment (L). CASBEE is the most heterogeneous tool because it presents a greater variety of issues, as observed in both Table 6 and Figure 1(a), but with a better distribution amongst indicator types as the number of issues addressed by Performance, Procedure and Feature is similar. The predominance of Performance is seen in 'Health and Comfort' and 'Energy Performance'. Feature indicators are mainly found in 'Water', 'Materials and Resources', while Procedural indicators are mainly present in 'Site Sustainability' and 'Waste'.

Aggregation and weighting. Aggregation and weighting are used when there are tradeoffs between the impacts considered. Weights typically vary with the scope of the assessment and are often subjective. These weightings do not always enjoy consensus between the tool's designers and tool users. However, the weighting process is inherent and a core step to sustainability evaluation, since it is responsible for establishing the overall performance score of the assessed building (Lee et al. 2002). In addition, weights vary over time as a consequence of market transformation, patterns and trends evolution (Todd, Pyke, and Tufts 2013). Different authors have tried to overcome this subjectivity. Malmqvist et al. (2011) used quantitative indicators, but still aggregation was qualitative. Within the same line of thought, Ding (2008) suggested the use of indicators instead of marks, but these would still need aggregation to reach the overall score through weights.

Each of the BSAT has its own aggregation and weighting system, as shown in Table 7. None of the systems has its weights expressly and scientifically determined, bringing back the question/doubt related to the subjectivity of the sustainability concept. CSH has both a credit scoring system and weighting factors. The former is used to balance issues within each category, while weights are used to aggregate categories into the final score. In

Table 7. BSAT levels of aggregation.

\begin{tabular}{lcl}
\hline $\begin{array}{l}\text { Assessment } \\
\text { method }\end{array}$ & $\begin{array}{c}\text { Levels of } \\
\text { aggregation }\end{array}$ & \multicolumn{1}{c}{ Aggregation details } \\
\hline CSH & 2 & $\begin{array}{l}\text { Issue - category - final score } \\
\text { LEED }\end{array}$ \\
SBTool $^{\text {PT }}$-H & 1 & Credits - final score \\
DGNB & 3 & Issue - indicator - category - final score \\
CASBEE & 1 & Issue - final score \\
& 5 & Detailed item - minor item - medium item - category - SQ and SLR - BEE \\
(final score)
\end{tabular}


addition, CSH encompasses mandatory credits as well as interchangeable ones. LEED, in turn, uses a simple process of summing up the credits achieved in each assessed criterion. As in CSH, LEED has few mandatory criteria that do not contribute with credits to the final score, while other criteria are interchangeable. During design, the actors involved can not only decide on the sustainability level aimed for the dwelling, but also pursue the criteria that will lead them to their goal. SBTool ${ }^{\mathrm{PT}}-\mathrm{H}$ adopted a weighting factor system, contrary to other systems where weights are determined through a panel of experts. The weights were established based on the principle of extent, intensity and duration of the impact assessed in each indicator. DGNB is also based on a weighting factor system, although each criterion is assigned with points and only then multiplied by a weighting factor. CASBEE has a complex and different aggregation system, when compared to other tools. It separately addresses the environmental quality of the house itself $(\mathrm{Q})$ and the environmental load imposed by the house on the external environment (L). Different levels are addressed in a different way. A numerical score scale (from 1 to 5 ) is used in lower level criteria. These values are then multiplied by weighting coefficients until reaching SQ (score for $\mathrm{Q}$ ) and SLR (score for $\mathrm{L}$ reduction), which may vary from 0 (zero) to 1. The overall score of the building is called Building Environmental Efficiency (BEE) and results from $\mathrm{Q} / \mathrm{L}=[25 \times(\mathrm{SQ}-1)] /[25 \times(5-\mathrm{SLR})]$. According to IBEC (2008), the weighting factors for major items were statistically determined through questionnaires to stakeholders, including owners, housing suppliers, administrative officials, and scholars, while medium and minor level weighting coefficients result from discussions between specialists.

In order to ease the comparison amongst BSAT weightings, Figure 2 presents the relative contributions of each main sustainability category to the overall sustainability score of each BSAT. Some adjustments were needed to adapt the schemes' specific categories to the ones adopted in this paper. EcoProP was not included in this comparison since it is not a rating system, and therefore has no weighting factors.

Figure 2 clearly shows the divergence in the weightings between the tools. The weighting within $\mathrm{CHS}$ and LEED appears to be the most alike while other tools are much more diverse. In the $\mathrm{SBTool}^{\mathrm{PT}}-\mathrm{H}$, the importance given to economic issues is quite evident,

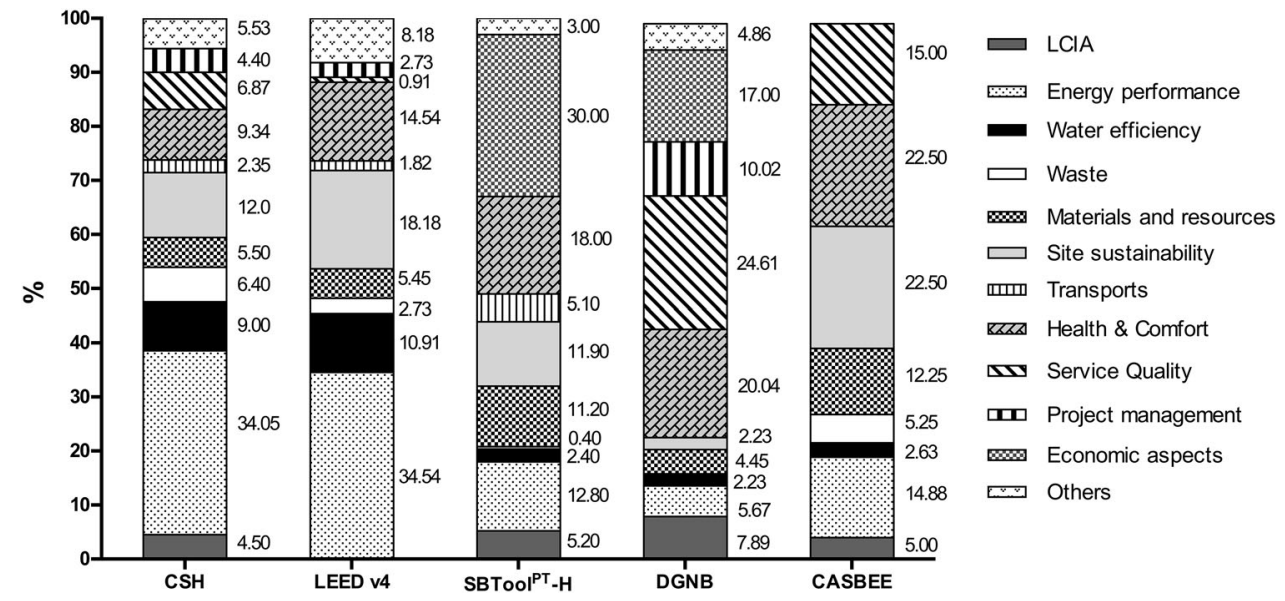

Figure 2. Distribution of BSAT weightings. 
whereas in DGNB 'Service Quality' issue is emphasised. CASBEE, with its different structure and weighting system, stands out by having a more balanced weight distribution, although it does exclude a few categories (Figure 2). On the other hand, CSH aggregates more categories to the final sustainability score.

Although it is not the only category within the Environmental dimension, 'LCA' is included in the BSAT with an influence of less than $10 \%$ on the overall sustainability score, with DGNB being the tool providing it with the highest rate (7.89\%). CHS and LEED give high relevance to Energy, attributing a weight to it that is superior to a third of the total score. An equivalent percentage is given by the SBTool ${ }^{\mathrm{PT}}-\mathrm{H}$ to economic aspects $-30 \%$. Other considered relevant aspects of the environmental dimension are 'Water Efficiency' and 'Site Sustainability'. 'Water Efficiency' is considered as more relevant by both CSH and LEED than by the other three BSATs. LEED (18.52\%) and CASBEE (22.50\%) give prominence to 'Site Sustainability', corresponding to almost twice the weight considered by CSH and SBTool ${ }^{\mathrm{PT}}$-H. Most of the 'Site Sustainability'-related aspects considered by DGNB are not considered in the overall sustainability score by the tool. However, some criteria from the issues that account for the final score in DGNB (2.23\%) were considered to be under the 'Site Sustainability' category. Briefly, environmental dimension is accounted for $72.6 \%$ in $\mathrm{CSH}, 71.82 \%$ in LEED, $40.00 \%$ in SBTool $^{\mathrm{PT}}-\mathrm{H}, 27.33 \%$ in DGNB and $62.50 \%$ in CASBEE.

The increasing importance of social aspects for sustainability is visible through the emphasis given to 'Health and Comfort', which is around $20 \%$ in SBTool ${ }^{\mathrm{PT}}-\mathrm{H}, \mathrm{DGNB}$ and CASBEE - the most recent tools - and slightly lower in LEED and CSH. Considering all categories under the social dimension, DGNB gives greater importance to it as this dimension is accounted for $55.67 \%$ of the overall sustainability score, followed by CASBEE with $37.50 \%$, SBTool $^{\mathrm{PT}}$-H with $30.00 \%$, LEED with $28.18 \%$ and, finally, CSH with $27.40 \%$.

Economic aspects are still one of the most important problems and dilemmas when dealing with sustainability. In fact, from these six BSAT just two account directly for it $\mathrm{SBTool}^{\mathrm{PT}}-\mathrm{H}(30.00 \%)$ and DGNB (17.00\%). Therefore, it is quite interesting that all the other methods consider themselves as 'sustainability' assessment methods. Economic aspects within sustainability are being discussed (CB Richard Ellis 2009; Eichholtz, Kok, and Quigley 2013). Beyond the scarce publications studying the effects of considering economic issues in sustainability, there are few that relate them to energy-efficiency measures (Bonakdar, Dodoo, and Gustavsson 2014; De Angelis, Pansa, and Serra 2014). BRE and Cyrill Sweett undertook a study showing that the environmental performance of a home building could be increased in 1-2 sustainability levels for less than 2\% additional cost (Abdul and Quartermaine 2014). However, considering this $2 \%$ initial cost increase in a life cycle could lead to a reduction in the operational costs, and thus lead to a decrease of the whole life cycle costs of the dwelling. Nevertheless, the social and cultural context to which these studies and these BSAT are applicable is important to bear in mind. 'Cultural Heritage' preservation and developing countries should have different approaches and, once more, weights should be adjusted to local realities. Moreover, when accounting for cultural heritage, only one of the tools included these issues in its assessment scheme - EcoProP. When accounting for both cultural and economic aspects, a balance needs to be found. These discussions point out the need for a comprehensive study on sustainability constraints, such as finding a balance between low environmental impact buildings, all the social pressures and 
Table 8. Rating and scoring levels.

\begin{tabular}{lll}
\hline Methodology & Value achieved & \multicolumn{1}{c}{ Qualitative scale } \\
\hline CSH & $36-47$ points & Level $1(\star)$ \\
& $48-56$ points & Level $2(\star \star)$ \\
$57-67$ points & Level $3(\star \star \star)$ \\
& $68-83$ points & Level $4(\star \star \star \star)$ \\
& $84-89$ points & Level $5(\star \star \star \star \star)$ \\
& $90-107$ points & Level $6(\star \star \star \star \star \star)$ \\
& $45-49$ points & Certified \\
LEED & $50-59$ points & Silver \\
& $60-79$ points & Gold \\
& $80+$ points & Platinum \\
& $P<.00$ & E \\
SBTool ${ }^{\text {PT }-H}$ & $.00 \leq P \leq .10$ & D \\
& $.10<P \leq .40$ & C \\
& $.40<P \leq .70$ & B \\
& $.70<P \leq 1.00$ & A \\
& $P>1.00$ & $A^{+}$ \\
DGNB & $\geq 50 \%$ & Bronze \\
& $\geq 65 \%$ & Silver \\
CASBEE & $\geq 89 \%$ & Gold \\
& BEE $<0.5$ & $C-$ Poor $(\star)$ \\
& $0.5 \leq B E E<1.0$ & $B^{-}-$Fairly poor $(\star \star)$ \\
& $1.0 \leq B E E<1.5$ & $B^{+}-$Good $(\star \star \star)$ \\
& $1.5 \leq B E E<3.0$ & A - Very good $(\star \star \star \star)$ \\
& BEE $\geq 3.0$ & S - Excellent $(\star \star \star \star \star)$ \\
\hline
\end{tabular}

the financial availability to implement and maintain the intended sustainability measures. The economic value of cultural heritage preservation is beginning to be discussed more widely (Tuan and Navrud 2008; Bowitz and Ibenholt 2009; Sodangi et al. 2014).

Beyond aggregation and weighting systems, rating levels are also quite different from tool to tool (Table 8). Notwithstanding, all tools present a qualitative scale, mostly intended for end-users to better understand the result and score achieved.

\section{When is the assessment performed?}

When observing Table 2, we can verify that BSATs are applicable to different life cycle stages. Yet, when looking specifically at the methodologies for dwellings, the applicability falls essentially to one of two phases: post-construction (new construction) or design phases. CSH, LEED, DGNB and CASBEE proclaim to be applied during design and after construction. However, their applicability in design is for designers to have an idea about the building performance, as no final certification is given at this phase. To obtain this certificate, the assessment needs to be repeated to some extent and verified after construction. $\mathrm{SBToo}^{\mathrm{PT}}-\mathrm{H}$ also follows this procedure. On the contrary, EcoProp (although not a rating method) was specifically developed to be used during pre-design and design phases to aid designers in the construction of a sustainable building and to know what to expect after construction (not being used in post-construction).

\section{Discussion}

This paper started by analysing existing BSAT schemes and then narrowed the scope of assessment to those that could be applied to single-family dwellings. The evaluation 
consisted in determining the differences amongst methodologies, considering: (i) the purpose of assessment; (ii) sustainability dimensions considered; (iii) indicators addressed; (iv) life cycle phases considered by the indicators; (v) type of indicators; (vi) measurements; (vii) aggregation processes and (vii) life cycle phases during which the assessment was carried out. The paper focused on the identification and comparison of the tools, and not their consequences, when applied to single-family buildings.

This work highlighted that, although the main objectives of the different methodologies are similar, the scope and means to achieve them are quite variable. When assessing the six BSATs, all, except EcoProP, intend to certify the buildings' sustainability, but only after construction. Although they can be applied during design, an effective certificate will only be issued after post-construction validation.

Multi-criteria assessment methods are needed to evaluate a building's sustainability in order to assure a realistic and holistic assessment. In addition, the life cycle phase during which the evaluation occurs plays an important role in implementing and achieving sustainability goals. Although early design stages are known to be crucial to a building's life cycle sustainability, only ATHENA, EcoProP and LEnSE were developed to be really applied in these phases. It is during early design stages that most design outcomes are settled and incorporated in the final design. Early planning phases play an important role in achieving building sustainability, as the potential of optimisation is higher, and the impacts of building changes and construction costs are lower at this point (Braganca, Vieira, and Andrade 2014; Kovacic and Zoller 2015). According to Petersen and Svendsen (2010), existing simulation tools tend to compare design alternatives rather than give actual advice on how to achieve a desirable performance, leading to extra time loss for designers to make iterations until a satisfactory result is reached. When choosing design options, complexity and costs are directly involved and depend on that. Creating different possibilities, comparing them and their performance is of major importance for designers. The importance of considering sustainability concepts at early design stages and the need for tools applicable to these phases has been discussed (Bogenstätter 2000; Jrade and Jalaei 2013; Markelj et al. 2014; Oti and Tizani 2015). All these authors, though focusing on the importance of sustainability rating systems, point out that these are not always applied to some crucial phases. Thus, BSAT must be introduced as early as possible to be truly useful, allowing interrelation between the design and assessment teams. Obviously, the assessment cannot rely on detailed design information before it has been generated. However, several analysed systems rely on detailed data or in the commitment to achieve it, as in the case of BREEAM/CSH, LEED, DGNB, SBTool ${ }^{\mathrm{PT}}-\mathrm{H}$ and OpenHouse. This precludes their effective application during early design. Although these tools are not applicable to conceptual phases, an assessment can be made using them at the final design phases. At this point, a preliminary sustainability score and certification can be produced, although it is not valid as the final certification until re-evaluation after construction. Design Certification is not the target of discussion in the literature but, as aforementioned, this phase is essential to the success of the implementation of sustainability measures. To what extent do measures in design change during/after construction? Should design teams be recognised for including sustainable principles at early design stages? Are they really implemented? Even if a building is designed and built to be sustainable, do users use it wisely and according to the principles underlying it? Or do they exclude that advantage and a 'sustainable' building becomes an ordinary building due to misguided use? All of these questions can 
be pointed out when discussing sustainability certification. Surprisingly, no study deals with the differences found between preliminary certification/assessment, post-construction certification and real-use assessment. This could be an interesting study to further understand how sustainability methodologies deal with the evolution of a building life cycle.

Considering sustainability as an interrelationship between environmental, social and economic concerns, all BSATs should consider them to some extent during the assessment. On the other hand, some might say that economic concerns can somehow be set aside if environmental and social concerns are assured. Nevertheless, only SBTool ${ }^{\mathrm{PT}}$ $H, D G N B$, EcoProP and LEnSE follow the first premise and assess the three sustainability pillars. All the others only consider environment and society except ATHENA, which only assesses environmental impacts.

The Weighting system is the part of the tools that ultimately defines the sustainability level of the building. There is no consensus either in the approach to finding the weights or in the weights to be given to each issue or category. None of the six BSATs analysed in detail presents the same aggregation and weighting system. When observing the weights assigned to the three pillars, environmental aspects tend to get more weight than social and economic ones. This might be due to the amount of existing research focused on buildings and life cycle environmental assessment. Within the environmental categories, Energy and Site Sustainability are amongst the most important categories for the set of BSAT studied. From the tools analysed, only DGNB gives higher importance to social issues than to environment. The SBTool ${ }^{\mathrm{PT}}$-H assigns equal weights to social and economic issues. The analysis of weights, weighting and scoring systems of each methodology shows that there is still a long way to go to reach a consensus in weights and importance given to each indicator in the evaluation of single-family buildings. Further investigation on how to objectively establish weights and scores is absolutely necessary.

Regarding the indicators assessed, CSH and EcoProP have the widest scope, while LEED has the smallest. Taking into consideration the rating systems, although the indicators addressed in DGNB are fewer than in $\mathrm{CSH}$, their distribution amongst the evaluated categories seemed to be more balanced. It not only assesses more issues under service quality but also includes economic aspects, which is not the case within CSH. However, it is noteworthy that each scheme acknowledges their local context. It is important to stress that the adaptation to the local context is crucial, and due to this fact BSATs are not exportable/importable without any adaptation. As aforementioned, only the SBTool method has been internationally developed to be specifically adapted to different countries and different realities.

Regarding the reported life cycle phases, EcoProP is the only methodology considering all phases. With regard to rating systems, DGNB and CASBEE consider more phases in their evaluation.

The study showed that none of the schemes is totally quantitative or qualitative. All have different types of indicators and different ways to measure them, even if the scope is the same. This means that measuring sustainability is still quite subjective, although there are now international standards trying to overcome these shortcomings. Nevertheless, each methodology has its own outline and approach to the assessment. LEED is based on a more Feature and 'Procedural methodology', having a much more immediate assessment. It can more easily guide designers to add/exclude a feature, and 
quickly know the effect it will have on the final score. Nevertheless, this might conceal results or real data (as consumptions) as it does not quantify the exact (or expected) performance of the building. SBTool ${ }^{\mathrm{PT}}-\mathrm{H}, \mathrm{DGNB}$ and EcoProP are based more on Performance indicators, trying to really assess the behaviour of the building. However, not all indicators can really assess the effect they are trying to measure. Instead, they evaluate a potential effect or a way to minimise it. For example, the SBTool ${ }^{\mathrm{PT}}-\mathrm{H}$ assesses the type of containers and selective collection of waste, instead of quantifying the real waste production. However, real waste production is very difficult to measure or predict, although having proper means that promote recycling and waste reduction helps in foreseeing that waste production will be reduced. Another example is the quantification of finishing materials that have low VOC emissions. The scope of the indicator is to assess indoor air quality, but instead of assessing the concentration level of volatile organic compounds (VOC) emissions or their effects, the use of finishing materials with low VOC emissions is promoted. Amongst the six methodologies evaluated, only $\mathrm{CSH}$ presents a balance between the three types of indicators - 6 Performance, 6 Feature and 6 Procedure/ Procedural.

The reliability of these methods can easily be discussed. Does their application truly promote sustainability? Are the addressed aspects enough to assure that? Are the results trustworthy? There are several questions that may emerge from this study to which the answer can be rather complex. The authors do not intend to defend a methodology that deprecates others.

This paper is aimed at presenting different perspectives for different situations. The applicability of the methodologies depends heavily on the local country constraints, on their development level, legal requirements and restrictions, cultural heritage or climatic conditions, as each methodology is tailored to the local conditions where it was developed and applied. Thus, sustainability assessment should be moulded to the reality of where it is being applied, but maintaining the same overall principles - and the interrelation and balance between environmental, social and economic constraints. Still, the implicit importance of balanced components should be adapted to local reality. For instance, if there are tight regulations regarding non-renewable energy consumption, then minimum requirements should be set in the building sustainability assessment. On the other hand, if water scarcity is an issue in a country, then the weight given to water aspects shall be relevant to the overall sustainability score.

\section{Conclusions}

All BSATs intend to assess and emphasize building sustainability quality, analysing a multidisciplinary group of issues. It is interesting to observe the differences within the methodologies and the aspects considered by each. Thus, it is of great interest to study them and understand the ins and outs of their frameworks and the main differences between them.

According to the assessment made, environmental concerns play a major role in the sustainability assessment of dwellings. Nevertheless, the more recent the tools or their versions are, the more the concerns related to social comfort, functional and technical aspects and economic issues are included in the assessment. The way issues are considered by the tools is significantly diverse, hindering any comparison of sustainability assessments made 
to different buildings and using different tools. In addition, variations in the purpose, scope, aggregation and weighting systems were found.

The characteristics and differences between the tools presented in this paper provide researchers and stakeholders with useful information for the development of new methods to quantify and aid the development of more sustainable built environment. Additionally, the paper raises concerns and questions that can encourage further research and development in the field of sustainability and home BSAT.

\section{Disclosure statement}

No potential conflict of interest was reported by the authors.

\section{Funding}

This work was supported by FCT (Fundação para a Ciência e a Tecnologia - Portugal) under Grant SFRH/BD/76043/2011 to Joana Bonifácio Andrade.

\section{ORCID}

Joana Andrade (iD http://orcid.org/0000-0002-4166-284X

Luís Bragança (D) http://orcid.org/0000-0003-4246-8157

\section{References}

Abdul, Yetunde, and Richard Quartermaine. 2014. Delivering Sustainable Buildings: Savings and Payback. Watford: IHS BRE Press.

Alyami, Saleh H., and Yacine Rezgui. 2012. "Sustainable Building Assessment Tool Development Approach." Sustainable Cities and Society 5: 52-62. doi:10.1016/j.scs.2012.05.004.

Andrade, Joana B., and Luis Bragança. 2012. "Sustainability Assessment and Standardisation - Steel Buildings." In Concepts and Methods for Steel Intensive Building Projects, edited by Heli Koukkari, Luis Bragança and Samir Boudjabeur, 213-224. Portugal: European Conventition for Constructional Steelwork (ECCS).

Araújo, Catarina, Manuela Almeida, and Luís Bragança. 2013. "Analysis of Some Portuguese Thermal Regulation Parameters." Energy and Buildings 58: 141-150. doi:10.1016/j.enbuild.2012.11.024.

ATHENA. 2014. "Athena Sustainable Materials Institute Web Page." Accessed May http://www. athenasmi.org/.

Barbosa, José Amarilio, Ricardo Mateus, and Luís Bragança. 2013. "Adaptation of SBToolPT to Office Buildings." International Journal of Sustainable Building Technology and Urban Development 4 (1): 89-97. doi:10.1080/2093761x.2012.759892.

Berardi, Umberto. 2012. "Sustainability Assessment in the Construction Sector: Rating Systems and Rated Buildings." Sustainable Development 20 (6): 411-424. doi:10.1002/sd.532.

Blok, Rijk, Emilia van Egmond, Mauritz Glaumann, and Helena Gervasio. 2011. "General Framework for Sustainability Evaluation of the Built Environment." In Summary Report of the Cooperative Activities of the COST Action C25 - Sustainability of Constructions - Integrated Approach to Lifetime Structural Engineering, edited by Luis Bragança, Heli Koukkari, Rijk Blok, Helena Gervásio, Milan Veljkovic, Zbigniew Plewako and Ruben Paul Borg, 3-30. Malta: Department of Civil \& Structual Engineering of Faculty for the Built Environment, University of Malta.

Bogenstätter, Ulrich. 2000. "Prediction and Optimization of Life-Cycle Costs in Early Design." Building Research \& Information 28 (5-6): 376-386. doi:10.1080/096132100418528. 
Bonakdar, Farshid, Ambrose Dodoo, and Leif Gustavsson. 2014. "Cost-Optimum Analysis of Building Fabric Renovation in a Swedish Multi-Story Residential Building." Energy and Buildings 84: 662-673. doi:10.1016/j.enbuild.2014.09.003.

Bowitz, Einar, and Karin Ibenholt. 2009. "Economic Impacts of Cultural Heritage - Research and Perspectives." Journal of Cultural Heritage 10 (1): 1-8. doi:10.1016/j.culher.2008.09.002.

BPIE (Buildings Performance Institute Europe) 2011. Europe's Buildings Under the Microscope - A Country-By-Country Review of the Energy Performance of Buildings. Brussels: BPIE.

Bradley, G. Guy, and Charles J. Kibert. 1998. "Developing Indicators of Sustainability: US Experience." Building Research \& Information 26 (1): 39-45. doi:10.1080/096132198370092.

Braganca, Luis, Susana M. Vieira, and Joana B. Andrade. 2014. "Early Stage Design Decisions: The Way to Achieve Sustainable Buildings at Lower Costs." The Scientific World Journal 8. doi:10.1155/2014/ 365364.

BRE Global Ltd. 2014. "BREEAM: the Environmental Assessment Method for Buildings Around The World." Accessed April. http://www.breeam.org/.

Bunz, K. R., G. P. Henze, and D. K. Tiller. 2006. "Survey of Sustainable Building Design Practices in North America, Europe, and Asia." Journal of Architectural Engineering 12 (1): 33-62. doi:10.1061/(ASCE) 1076-0431(2006)12:1(33).

Castro, Mariade Fátima, Ricardo Mateus, and Luís Bragança. 2014. "A Critical Analysis of Building Sustainability Assessment Methods for Healthcare Buildings." Environment, Development and Sustainability: 1-32. doi:10.1007/s10668-014-9611-0.

CB Richard Ellis. 2009. Who Pays for Green? The Economics of Sustainable Buildings. London: CB Richard Ellis.

Chandratilake, S. R., and W. P. S. Dias. 2013. "Sustainability Rating Systems for Buildings: Comparisons and Correlations." Energy 59: 22-28. doi:10.1016/j.energy.2013.07.026.

Danatzko, Joseph M. 2010. Sustainable Structural Design. Columbus, OH: The Ohio State University.

De Angelis, Enrico, Giorgio Pansa, and Ermanno Serra. 2014. "Research of Economic Sustainability of Different Energy Refurbishment Strategies for an Apartment Block Building." Energy Procedia 48: 1449-1458. doi:10.1016/j.egypro.2014.02.164.

Department for Communities and Local Government. 2010. Code for Sustainable Homes - Technical Guide. London: Communities and Local Government Publications.

Ding, Grace K. C. 2008. "Sustainable Construction - The Role of Environmental Assessment Tools." Journal of Environmental Management 86 (3): 451-464. doi:10.1016/j.jenvman.2006.12.025.

Dobbelsteen, Andy van den, and Stefan van Uffelen. 2008. "Model Comparison of the Duch Green Building Tool." Dutch Green Building Council, Climate Design section, Faculty of Architecture of Techincal University of Delft, Delft.

Eco-Quantum. 2013. "EcoQuantum." Accessed December. http://www.ivam.uva.nl/index.php?id= $2 \& L=1$.

Eichholtz, Piet, Nils Kok, and John M. Quigley. 2013. "The Economics of Green Building." Review of Economics and Statistics 95 (1): 50-63. http://www.mitpressjournals.org/loi/rest.

Erlandsson, Martin, and Mathias Borg. 2003. "Generic LCA-Methodology Applicable for Buildings, Constructions and Operation Services - Today Practice and Development Needs." Building and Environment 38 (7): 919-938. doi:10.1016/s0360-1323(03)00031-3.

Fowler, K. M., and E. M. Rauch. 2006. Sustainable Building Rating Systems Summary. Richland, WA: Pacific Northwest National Laboratory.

German Sustainable Building Council. 2010. DGNB System Brochure: Excellence Defined - Sustainable Building with a Systems Approach. Stuttgart: DGNB GmbH.

German Sustainable Building Council. 2014. "DGNB System." Accessed January. http://www.dgnb. de/_en/certification-system/index.php.

Haapio, Appu, and Pertti Viitaniemi. 2008. "A Critical Review of Building Environmental Assessment Tools." Environmental Impact Assessment Review 28 (7): 469-482. doi:10.1016/j.eiar.2008.01.002.

IBEC (Institute for Building Environment and Energy Conservation). 2008. CASBEE for Home (Detached House) - Technical Manual 2007 Edition. 1st ed. Tokyo, Japan: IBEC.

iiSBE (International Initiative for a Sustainable Built Environment). 2014. "iiSBE SBTool 2012." Accessed May. http://www.iisbe.org/. 
JaGBC (Japan GreenBuild Council), and JSBC (Japan Sustainable Building Consortium). 2014. "Comprehensive Assessment System for Built Environment Efficiency (CASBEE)." Accessed March. www.ibec.or.jp/CASBEE/english/index.htm.

Jrade, Ahmad, and Farzad Jalaei. 2013. "Integrating Building Information Modelling with Sustainability to Design Building Projects at the Conceptual Stage." Building Simulation 6 (4): 429-444. doi:10.1007/s12273-013-0120-0.

Kaatz, Ewelina, David S. Root, Paul A. Bowen, and Richard C. Hill. 2006. "Advancing Key Outcomes of Sustainability Building Assessment." Building Research \& Information 34 (4): 308-320. doi:10.1080/ 09613210600724608.

Kovacic, Iva, and Veronika Zoller. 2015. "Building Life Cycle Optimization Tools for Early Design Phases." Energy 92, Part 3:409-419. doi:10.1016/j.energy.2015.03.027.

Lee, W. L. 2013. "A Comprehensive Review of Metrics of Building Environmental Assessment Schemes." Energy and Buildings 62. doi:10.1016/j.enbuild.2013.03.014.

Lee, W. L., C. K. Chau, F. W. H. Yik, J. Burnett, and M. S. Tse. 2002. "On the Study of the Credit-Weighting Scale in a Building Environmental Assessment Scheme." Building and Environment 37 (12): 1385-1396. doi:10.1016/s0360-1323(02)00006-9.

LEnSE Partners. 2006. "Sustainability Assessment of Buildings - Issues, Scope and Structure." Methodology Development Towards a Label for Environmental Social and Economic Buildings, LEnSE Project, Belgium.

Malmqvist, T., M. Glaumann, Å. Svenfelt, P. O. Carlson, M. Erlandsson, J. Andersson, H. Wintzell, G. Finnveden, T. Lindholm, and T. G. Malmström. 2011. "A Swedish Environmental Rating Tool for Buildings." Energy 36 (4): 1893-1899. doi:10.1016/j.energy.2010.08.040.

Markelj, Jernej, Manja Kitek Kuzman, Petra Grošelj, and Martina Zbašnik-Senegačnik. 2014. "A Simplified Method for Evaluating Building Sustainability in the Early Design Phase for Architects." Sustainability 6 (12): 8775-8795. doi:10.3390/su6128775.

Mateus, Ricardo, and Luís Bragança. 2009. Manual de avaliação SBTool ${ }^{P T}-H$. V2009/2. In. Portugal: iiSBE Portugal.

Mateus, Ricardo, Luis Braganca, and Heli Koukkari. 2008. "Sustainability Assessment and Rating of Portuguese Buildings." In CIB Co-sponsored: World SB08 Melbourne: World Sustainable Building Conference, edited by Greg Foliente, Thomas Luetzkendorf, Peter Newton, and Phillip Paevere, 959-966. Melbourne: CSIRO (Commonwealth Scientific and Industrial Research Organisation).

OpenHouse. 2013. "Open House Project." Accessed June 2013. http://www.openhouse-fp7.eu/.

Oti, A. H., and W. Tizani. 2015. "BIM Extension for the Sustainability Appraisal of Conceptual Steel Design." Advanced Engineering Informatics 29 (1): 28-46. doi:10.1016/j.aei.2014.09.001.

Petersen, S., and S. Svendsen. 2010. "Method and Simulation Program Informed Decisions in the Early Stages of Building Design." Energy and Buildings 42 (7): 1113-1119. doi:10.1016/j.enbuild.2010.02. 002.

Sodangi, Mahmoud, Mohd Faris Khamdi, Arazi Idrus, Dabo B. Hammad, and Abdullahi AhmedUmar. 2014. "Best Practice Criteria for Sustainable Maintenance Management of Heritage Buildings in Malaysia." Procedia Engineering 77: 11-19. doi:10.1016/j.proeng.2014.07.017.

Tarja Häkkinen et al. 2012. Sustainability and Performance Assessment and Benchmarking of Buildings Final Report, SuperBuildings Project. Finland: VTT Technical Research Centre of Finland.

Todd, Joel Ann, Chris Pyke, and Robert Tufts. 2013. "Implications of Trends in LEED Usage: Rating System Design and Market Transformation." Building Research \& Information 41 (4): 384-400. doi:10.1080/09613218.2013.775565.

Tuan, Tran Huu, and Stale Navrud. 2008. "Capturing the Benefits of Preserving Cultural Heritage." Journal of Cultural Heritage 9 (3): 326-337. doi:10.1016/j.culher.2008.05.001.

U.S. Green Building Council. 2014. "LEED homepage." Accessed January. http://www.usgbc.org/leed.

U.S Green Building Council. 2014. "LEED v4 for Homes Design and Construction." Accessed June. http://www.usgbc.org/articles/getting-know-leed-homes-design-and-construction.

VTT, Technical Research Centre of Finland. 2004. "EcoProp Brochure." In. Filand.

VTT, Technical Research Centre of Finland. 2013. "EcoProP 4.3.1 [software]." In. Finland.

Wallhagen, Marita, Mauritz Glaumann, Ola Eriksson, and Ulla Westerberg. 2013. "Framework for Detailed Comparison of Building Environmental Assessment Tools." Buildings 3 (1): 39-60. 